Научная статья

УДК: 81: 070

doi: $10.18101 / 2305-459 X-2021-1-16-24$

\title{
СУБЪЯЗЫКОВОЕ ВЗАИМОДЕЙСТВИЕ В ТЕКСТАХ РЕГИОНАЛЬНОЙ РЕКЛАМЫ (НА МАТЕРИАЛЕ СООБЩЕНИЙ, СОЗДАННЫХ В ФОРМАТЕ ВАЙНОВ)
}

\author{
(C) Харанутова Дарима Шагдуровна \\ доктор филологических наук, доцент, \\ Бурятский государственный университет имени Доржи Банзарова \\ Россия, 670000, г.Улан-Удэ, ул. Ранжурова, 6 \\ dkharanutova@mail.ru. \\ (C) Доржиев Бато Жаргалович \\ аспирант, \\ Бурятский государственный университет имени Доржи Банзарова \\ Россия, 670000, г.Улан-Удэ, ул. Ранжурова, 6 \\ bato1995@yandex.ru
}

\begin{abstract}
Аннотация. Работа посвящена проблеме многоречия, основной приметой которого является сосуществование единиц литературного языка и специфических единиц социальных субъязыков, под которыми понимаются разновидности языка. Субъязыковое взаимодействие исследуется в рекламном тексте Республики Бурятия (на материале собранной картотеки транскриптов (расшифрованных текстов) рекламных сообщений, созданных в формате вайнов (на примере аккаунта @chi_va_03). Язык рекламного текста максимально приближен к языку, на котором говорят потребители. По мнению авторов, используемая в вайнах простая разговорная речь является отражением разговорной речи молодых людей до 35 лет нашего региона. Выявлены и описаны основные разновидности многоречия в региональных рекламных сообщениях, созданных в формате вайнов: просторечные вкрапления, слова и выражения, слова из молодежного жаргона, сленговые словечки. К особенностям разговорной речи, звучащей в вайнах, авторы относят и регионализмы.

Ключевые слова: многоречие, субъязыки, вайны, разговорная речь, рекламные сообщения, молодежный жаргон, просторечие, регионализмы.
\end{abstract}

\section{Для цитирования}

Харанутова Д. Ш., Доржиев Б. Ж. Субъязыковое взаимодействие в текстах региональной рекламы (на материале сообщений, созданных в формате вайнов) // Вестник Бурятского государственного университета. Язык. Литература. Культура. 2021. Вып. 1. С. 16-24.

Процесс демократизации русского языка характеризуется тенденцией к развитию многоречия, особенностью которого является сосуществование единиц литературного языка и специфических единиц социальных субъязыков. На основе субъязыкового взаимодействия формируется в речевой практике факт своеобразного многоречия (полиглоссии). Субъязыки, вслед за Ю. Б. Скребневым, мы понимаем как разновидности русского национального языка, «условно замкну- 
Д. Ш. Харанутова, Б. Ж. Доржиев. Субъязыковое взаимодействие в текстах региональной рекламы (на материале сообщений, созданных в формате вайнов)

тые и самодовлеющие системы, полностью удовлетворяющие целям общения в данной речевой сфере» [10, с. 103].

Проблемы многоречия поднимались в работах И. Т. Вепревой [3], Н. А. Купиной [7], Ю. Б. Пикулевой [1] и др. Многоречие особенно ярко проявляется в отечественном рекламном дискурсе. «Ориентированный на продвижение товаров и услуг, формирующий ценности и установки общества потребления, отечественный рекламный дискурс отражает векторы развития российского информационного поля» ${ }^{1}$. Язык рекламного сообщения должен быть максимально приближен к языку, на котором говорят потенциальные потребители или покупатели.

Рассмотрим факт субъязыкового взаимодействия на материале устных рекламных сообщений юмористического характера, созданных в формате вайнов. В настоящее же время вайнами (англ. vine, по названию мобильного приложения «Vine») называют короткометражные видеоролики, которые выкладывается в Инстаграм либо в другие социальные сети [9]. В основе рекламных видеороликов лежат совершенно обычные бытовые ситуации, которые подаются в юмористическом ключе. В Бурятии чаще всего выпускают популярные вайнеры - резиденты команды КВН «Хараморин», представленные в высшей лиге Клуба веселых и находчивых (профиль в социальной сети Инстаграм - @chi_va_03, аккаунт - более сорока тысяч подписчиков). Следует признать, что бурятские вайнеры довольно успешно работают над созданием рекламного продукта (CHIVA PRODUCTION реклама).

Наш выбор определяется тем, что в вайнах записана живая звучащая речь, отражающая русскую речь нашего региона и, безусловно, свидетельствующая об активных субъязыковых контактах. Попутно отметим, что научное описание рекламных сообщений в формате вайнов региона находится в стадии накопления материала и систематизации расшифрованных текстов (транскриптов) рекламных сообщений, созданных в формате вайнов.

Популярность рекламных вайнов объясняется их четкой направленностью на целевую аудиторию, что соответствует установке, что в «рекламном дискурсе должен учитываться образ целевого адресата, его гендерный, возрастной статус, его социально-статусная характеристика» ${ }^{2}$. Кстати, если ранее считалось, что целевым адресатом текстов рекламных сообщений, созданных в формате вайнов, в большинстве является молодежная аудитория (возраст от 14-15 до 30-35 лет), то в настоящий момент очевиден тот факт, что целевая аудитория расширяется. Среди активных подписчиков можно встретить и людей старше пятидесяти лет. Справедливости ради надо отметить, что все же наиболее активными подписчиками являются представители молодежной аудитории.

Понятно, что целевой адресат требует имитации неформального общения с ним. Вайнеры строят свою речь как речь в общении со «своими», в видеоролике они демонстрируют раскованность, непосредственность, спонтанность, в связи с

1 Свободная энциклопедия интернета «Викиреальность». URL: http://www.wikireality.ru/wiki/Вайн (дата обращения: 20.01.2021). Текст: электронный.

${ }^{2}$ URL: https://instagram.com/chi_va_03 (дата обращения: 28.01.2021). Текст: электронный. 
чем в рекламном продукте мы наблюдаем речь, максимально приближенную к устной разговорной речи молодежи.

По мнению И. Т. Вепревой, формирование общего жаргона связано с молодежным субъязыком. «Продуктивное обращение к молодежной речи объясняется демократизацией современного русского языка, активно поддерживаемой данной возрастной группой россиян» [3, с. 61].

Итак, создание непринужденной обстановки предполагает употребление вайнерами в рекламных текстах стилистически сниженных единиц, широко употребительных в непринужденной речи современных носителей русского языка. Не секрет, что современный говорящий активно пользуется сниженной лексикой устной речи. Соответственно, для рекламы, ориентированной на молодежную аудиторию, характерны просторечные языковые единицы.

Приведем в качестве примера текст рекламного сообщения в формате вайнов (реклама интернет-провайдера «Телеос-1»), который достаточно наглядно демонстрирует широкое использование разговорных средств, создающих иллюзию непринужденности (просторечные слова, выражения выделяются знаком *):

$\boldsymbol{A}$. (А - парикмахер обращается к вошедшему клиенту Б) 3дравствуйте//

Б. Это парикмахерская?

A. Hет / это барбершоп//

Б. $Ч \ddot{e}^{*}$ ?

A. Ну/ барбершоп / в переводе барбер «парик» / шоп «махерская»//

Б. Получается парикмахерская?

A. A /ну-да*// Получается у меня парикмахерская / Воду пить будете?

Б. Не-не / пасибо*//

A. Нy / тогда пойдёмте /голову помоем//

Б. А/ подождите/ А правду говорят/ что у вас стрижка 20 рублей стоит?

A. Ну-да*/ Я просто начинающий парикмахер/ А/ кстати/ как стричься-то бydeme?

Б. Аааа/ можно мне модельную//

A. Аха* /конечно// Модельную?/ Так / щас-щас*// Я же говорю/ начинающий//

*(печатает на клавиатуре и говорит вслух: «Как сделать модельную причес$\kappa y ? »$

A. Ona*// Так/ щас-щас*/ загрузится/ аха*/ щас*//. Так/ давай/ давай / давай / так// Щас-щас*/ еще чуть-чуть// Так/ O/ всё// Загрузилось// Ну-че*/ давайте//

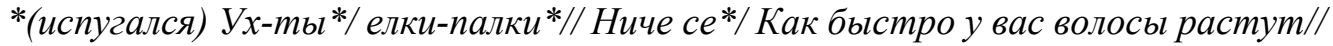

Б. Нет/ это просто у вас /интернет очень медленный//

A. Не/ ну какой есть/ такой есть/ Быстрее не бывает//

Б. Бывает/ Телеос-1//

A. Че* за Телеос//

Рекламный текст

Быстрый интернет делает жизнь удобнее. Телеос-1 не даст зависнуть ${ }^{*}$ интернету и ТВ. Подключайся прямо сейчас! Телефон 330-330.

Итак, речь обоих собеседников (А и Б) изобилует просторечными вкраплениями, которые повседневно используются в разговорной речи: щас-щас, че, yx-mbl, елки-палки, ниче се, аха. Такая форма подачи применяется намеренно, для более 
Д. Ш. Харанутова, Б. Ж. Доржиев. Субъязыковое взаимодействие в текстах региональной рекламы (на материале сообщений, созданных в формате вайнов)

непринужденной подачи предлагаемой услуги, как «свой» «своему». Ведь «свой» не будет обманывать «своего». Хотелось бы отметить, что погоня за такой «непринужденностью» в некоторых вайнах приводит к перебору в речи просторечных слов, выражений и вкраплений.

С другой стороны, в современной разговорной речи системно представлены стилистически сниженные единицы, нередко несущие на себе отпечаток определенной социальной среды. Такие социально отмеченные лексемы снабжены соответствующими пометами, которые позволяют увидеть качественное разнообразие лексикона, многоречие носителей литературного языка.

Итак, имеющиеся транскрипты региональных рекламных сообщений позволяют воссоздать некий срез речи носителя русского языка нашего региона в возрасте от 15 до 35 лет.

Помимо просторечных вкраплений, слов и выражений в рекламных сообщениях используются и жаргонизмы.

Например, в приведенном выше рекламном сообщении используется компьютерный жаргон зависнуть, причем это слово используется не в самом диалоге, а в официальном рекламном тексте. Скорее всего оно употребляется здесь для того, чтобы лучше донести смысл этого сообщения до потенциальных потребителей.

Использование специфической лексики профессиональных субъязыков позволяет адресовать информацию целевому адресату. Так, для увлекающихся современными информационными технологиями и компьютерными играми будет понятна реклама клуба виртуальной реальности «Gravity», где используются помимо просторечных слов и слова молодежного сленга [выделяются знаком *** и подчеркиванием] и узкоспециальная лексика [выделяются знаком **** и подчеркиванием]:

*звуки компьютерных игр

A. Хахаха/ Понял, кто тут главный?

Б. Давай еще раз/

*зукки компьютерных игр

A. Лузер!***/

Б. Еще раунд!

*звуки компьютерных игр

A. Изи катка!***/Одной левой/ Сидя/ прикинь/** Еще и без очков/ прикинь ${ }^{* *}$ ! Нет / ну ты играть-то будешь нет?

Б. Сльишь тын! (просторечие) Герой,/ иди сюда/ Поборемся?

A. Э-эй*/ После драки контроллерами **** не машут!

$<\ldots>$

A. Эй/ подожди/ Tbl кепку забыл?

Б. Нен/ вот моя кепка//

A. А знаешь /почему я тебя выцграл ***?

Б. Почему?

A. Потому что я/ здесь админ 
Рекламный текст

Gravity - клуб виртуальной реальности. Компьютерные игры и другие развлечения в формате полного погружения. Окунись в удивительный мир вместе с друзьями! Улицча Ключевская, 548.

Как видим, для увлекающихся компьютерными играми будет понятно переданное на профессиональном субъязыке рекламное сообщение о клубе виртуальной реальности «Gravity», где помимо просторечной лексики звучат слова из молодежного сленга: лузер, изи катка. Слово лузер (loser 'англ. неудачник') употребляется в шутливо-ироничной форме в адрес тех ребят, кто постоянно проигрывает игру. Выражение же изи катка используют геймеры в значении «легко выигранный матч». В рекламном тексте клуба виртуальной реальности мы можем наблюдать употребление узкоспециализированной лексики типа контроллеpbl, админ. Жаргонное слово админ, образованное способом сокращения слова администратор, активно используется в современном компьютерном сленге для обозначения руководителя компьютерной игры, человека, следящего за игрой. Игровой контроллер - это «устройство ввода информации, которое используется в компьютерных играх» [4]. Как видим, прагматический эффект достигается общей шутливо-разговорной тональностью.

Процесс жаргонизации русского языка, проникновение жаргонизмов в литературно-разговорную речь, в книжную (политическую, публицистическую, художественную) и др. - это также результат демократизации языка. «Лингвоэкологическая квалификация процесса жаргонизации литературного языка и коммуникативно-прагматическая квалификация этого процесса не сходятся: позволительность низкого уровня зачастую подкрепляется установкой адресанта на взаимодействие с адресатом, коммуникативное сотрудничество и обратную связь. Многоречие в таких случаях выступает как стратегически заданный способ «согласования коммуникативных действий» [1, с. 219]. Заметим, в рекламных сообщениях также наблюдается некий перебор с жаргонизмами (выделяются знаком* и подчеркиванием).

Реклама барбершопа «Borodach»

A. Вот такие!

Б. Че*/ реально-таки*/че ли? *

A. Судя по инстаграму/ вашен соски*/

Б. Я тебе так скажу/ ты по инстаграму ваще* людей не суди/ понял/ Даже ты в инстаграме красивый//

A. Не-не*/ они вконтакте ниче такие *//

Б. Не*, ну если вконтакте, то базара нет $*$ //

B. Не* ну на самом деле они еще в жизни ниче такие*//

A. Ты откуда их знаешь?

В. Они же одноклассницы мои/

Б. Че* молчал-то? Валим ${ }^{*}$ быстрее тогда!

A. Пойдем быстрее!

B. Не*/ подождите/ пацаны// А можно тогда резко * зайду подстригусь, $a$ ?

Б. В смысле подстригусь, а? Мы же опаздываем! Быстрее давай!

B. Ну, мне не удобно будет таким обросиим, ну, перед ними. 
Д. Ш. Харанутова, Б. Ж. Доржсев. Субъязыковое взаимодействие в текстах региональной рекламы (на материале сообщений, созданных в формате вайнов)

Б. Ой *передразнивает. Давай только быстрее, мы опаздываем!

$<\ldots .>$

К сожалению, авторы в рекламных сообщениях в погоне за привлечением подписчиков иногда идут и на употребление ругательств, заменителей нецензурных слов (выделяются знаком **)

Б. Да/ ваще*/ по фигу** / Нам/ главное/ побыстрее/ Очень торопимся/ пожалуйста/l

B. Ну всё/ паианы/ подстригся/ пойдем//

Б. Че* так быстро-то/ Сережа?

A. Может ты себе бороду еще подравняешь/ a?

Б. Блин **/ из-за твоей бороды проиграл/ Реально* подравняй бороду, а.

В. Ну все, паианы, я готов, пойдемте.

A. He/ $\mathrm{m} /$, че-то ваще */ быстро!

Б. Серега/ ты реально какой-то уставший/ Маску себе сделай/ а!?

В. Да я подстригся/, побрился/маску себе уже сделал/Пойдёмте//

A. Сльши / Че-то* он ващен/ реально* красавчиком стал/ Может, тоже подстригемся* / a?

Б. Да ладно, кого тын! Почли уже*/ время//

Рекламный текст

Барбершоп «Borodach» - выбор настоящих мужчин! Стрижки, бритье и другие услуги в самом иентре города! Улииа Куйбышева, 20. Остановка Гостиные ряды.

В данном примере можно наблюдать большое количество просторечных языковых единиц, жаргонизмов и даже ругательств, что существенно снижает уровень устной речи. Использование в речи жаргонизмов как соски, базара нет, резко зайду (в данном контексте это также слова молодежного жаргона), просторечных вкраплений и выражений ваще, ниче такие, короче, ругательств ни фuга, по фигу рисуют невысокой социально-статусный портрет потенциального клиента.

С другой стороны, сниженная лексика здесь употребляется неспроста. Это объясняется тем, что в барбершопе цены на услуги существенно выше, нежели в обычных парикмахерских. Построение диалогов подобным образом дает посыл потенциальным клиентам на интуитивном уровне, что услуги барбершопа доступны не только для мужчин с достатком выше среднего, но и для людей, у которых заработок ниже.

Проникновение в массовую рекламную коммуникацию социально отмеченных средств, понятное и оправданное с маркетинговой точки зрения, нередко оценивается специалистами-языковедами как проявление жаргонизации и вульгаризации русского языка [5, с. 183].

Многоречие формируется в поликультурном обществе, каковым является наша республика. По словам Ю. М. Лотмана, «реализуются стыковки различных национальных, социальных, стилевых кодов и текстов» [8, с. 35], в связи с чем взаимодействие различных видов лингвокультур образует специфику коммуникативно-культурного пространства. 
В русской речи нашего региона постоянно звучат регионализмы, под которыми понимаются отдельные лексические единицы местной разговорной речи $[11$, c. 4$]$. Среди регионализмов особое место занимают заимствования из бурятского языка. Основной причиной проникновения бурятских слов является безальтернативность, русским языком заимствуются слова, распространенные в быту, например, бууза `мясное блюдо', шулэн ‘бульон', архи `водка', аршан `минеральная вода` и т. д. Для носителей русского языка других регионов такие слова являются экзотизмами, для жителей же Бурятии это регионализмы. И рекламные тексты, в частности, тексты рекламных сообщений в формате вайнов - тому подтверждение.

Проиллюстрируем данный факт на рекламе унтов «Дулаан»

(Под мотив песни HammAli\&Navai):

Унты, унтыл/ унтыл/ унтыл/ Дулаан!

Так зачепило/

Унтыл, унтыл, унтыл, унтыл/ Дулаан//

Мыз закупились/

Унты, унтыл, унтыл, унтыл/ Дулаан//

Готовь унтыл летом/

Унтыл, унтьл/ Унтыл, унтыл/ Дулаан/ дулаан//

Благодаря рекламе про унты «Дулаан» и рекламе про нагревательные печи - котлы фирмы «Дулаан», вряд ли можно найти в Бурятии человека, не знающего значение слова дулаан, что означает «теплый, тепло» [2, с. 300]. Считаем, что это слово наравне с другими регионализмами типа сагааловка, архи, милан прочно вошло в русскую речь нашего региона.

Регионализмы создают свой особый колорит речи носителей русского языка и свидетельствуют о взаимовлиянии и взаимодействии языков, функционирующих в нашем регионе. Надо отметить, что регионализмы вносят свой голос в многоречное пространство рекламного дискурса.

Итак, современное рекламное пространство характеризуется многоголосием, в котором сосуществуют разные субъязыки: переплетаются в общем хоре голосов просторечные слова и выражения, словечки из молодежного жаргона, специфическая лексика из профессионального субъязыка, регионализмы. Тональность рекламных сообщений созвучна речи современного носителя русского языка нашего региона в возрасте до 35 лет, так как аудитория у вайнеров молодежная. Безусловно, рекламные вайны являются отражением русской разговорной речи нашего региона.

\section{Литература}

1. Борисова И. Н. Русский разговорный диалог: структура и динамика. Екатеринбург: Изд-во Урал. ун-та, 2001. 320 с. Текст: непосредственный.

2. Шагдаров Л. Д., Черемисов К. М. Бурятско-русский словарь: в 2 т. Т. 1. А-Н. Улан-Удэ: Республиканская типография, 2006. 636 с. Текст: непосредственный.

3. Вепрева И. Т. Метаязыковые измерения многоречия // Русский язык в многоречном социокультурном пространстве: [монография]. Екатеринбург: Изд-во Урал. ун-та, 2017. С. 51-68. Текст: непосредственный. 
Д. Ш. Харанутова, Б. Ж. Доржиев. Субъязыковое взаимодействие в текстах региональной рекламы (на материале сообщений, созданных в формате вайнов)

4. Карабань Н. А. Реклама в аспекте культуры речи // Рекламный дискурс и рекламный текст: [монография]. Волгоград: Перемена, 2010. С. 177-189. Текст: непосредственный.

5. Кронгауз М. А. Русский язык на грани нервного срыва. Москва: Знак: Языки славянских культур, 2007. 232 с. Текст: непосредственный.

6. Купина Н. А., Шалина И. В. Современное просторечие: взгляд изнутри // Русский язык в научном освещении. 2004. № 1(7). С. 23-62. Текст: непосредственный.

7. Лотман Ю. М. Символика Петербурга и проблемы семиотики города // Труды по знаковым системам. Семиотика города и городской культуры. Тарту: Изд-во Тартуского университета, 1984. Вып. 664. С. 30-45. Текст: непосредственный.

8. Пикулева Ю. Б. Многоречие в текстах рекламы // Русский язык в многоречном социокультурном пространстве: [монография]. Екатеринбург: Изд-во Урал. ун-та, 2017. С. 134-145. Текст: непосредственный.

9. Скребнев Ю. М. Очерки теории стилистики. Горький: Горьковск. гос. пед. ин-т иностр. яз., 1975. 175 с. Текст: непосредственный.

10. Торохова Е. А. Региональный вариант русского литературного языка, функционирующий на территории Удмуртии: социолингвистический аспект: автореферат диссертации на соискание ученой степени кандидата филологических наук. Ижевск, 2005. 25 с. Текст: непосредственный.

11. Шалина В. И. Просторечие на стыке лингвокультур // Русский язык в многоречном социокультурном пространстве: [монография]. Екатеринбург: Изд-во Урал. ун-та, 2017. С. 87-102. Текст: непосредственный.

Статья поступила в редакцию 29.01.2021; одобрена после рецензирования 24.02.2021; принята к публикации 05.03.2021.

\section{SUB-LINGUISTIC INTERACTION IN THE TEXTS OF REGIONAL ADVERTISING (THE CASE OF MESSAGES CREATED IN VINE FORMAT)}

Darima Sh. Kharanutova

Dr. Sci. (Phil.), A/Prof.,

Dorzhi Banzarov Buryat State University

6 Ranzhurova St., Ulan-Ude 670000, Russia

dkharanutova@mail.ru.

Bato Zh. Dorzhiev

Research Assistant,

Dorzhi Banzarov Buryat State University

6 Ranzhurova St., Ulan-Ude 670000, Russia

bato1995@yandex.ru

Abstract. The article is devoted to the problem of linguistic diversity; its main feature is the coexistence of literary language units and specific units of social sublanguages, which are understood as varieties of language. We have studied sublanguage interaction in the advertising texts of the Republic of Buryatia (based on the material collected from the card-index of transcripts (decrypted texts) of advertising messages created in vine format (for example,@ @ chi_va_03 account). The language of the advertising text is as close as possible to the language spoken by consumers. In our opinion, the simple colloquial 
speech used in vines is a reflection of the colloquial speech of young people under the age of 35. We have identified and described the leading varieties of vernacular in regional advertising messages created in vine format: colloquial inclusions, words and expressions, words from youthspeak, slang words. We consider regional dialects as the peculiarities of colloquial speech in vaines.

Keywords: polyphony; sublanguages; vines; colloquial speech; advertising messages; youthspeak; vernacular; regional dialects.

For citation

Kharanutova D. Sh., Dorzhiev B. Zh. Sub-Linguistic Interaction in the Texts of Regional Advertising (the case of messages created in vine format). Language. Literature. Culture. 2021; 1: 16-24 (In Russ.).

The article was submitted 27.01.2021; approved after reviewing 18.02.2021; accepted for publication 05.03.2021. 